\title{
Locomotion in the Biology of Large Aquatic Vertebrates
}

\author{
Paul W. Webb \\ Department of Biology and School of Natural Resources \\ University of Michigan. Ann Arbor, Michigan 48109.1115, USA, and \\ Ministry of Agriculture. Fisheries and Food. Fisheries Laboratory \\ Lowestoft, Suffolk NR33 OHT. England \\ VIVIAN DE BUFFRENIL \\ Museum National d'Histoire Naturelle, 75005 Paris, France
}

\begin{abstract}
As aquatic vertebrates increase in size, hydrofoils, which use lift to generate thrust, are increasingly used as propulsors. One factor affecting the magnitude of the lift force is the area of the propulsor. Resistance to cruising and sprints is mainly due to drag, but inertia is important during maneuvers when animals accelerate or turn. The inertia of the body and entrained water, which is proportional to body volume, resists acceleration. Because a thrust that is proportional to surface area is used to maneuver a resistance that is proportional to volume, acceleration performance and maneuverability are expected to decline with increasing size. This trend is ameliorated to some extent by the high swimming speeds attainable by warm-bodied vertebrates and the reduced resistance to acceleration characteristic of the skeletons of dolphins and ichthyosaurs. Maneuvers are essential for capture of elusive prey and avoidance of predators. As they increase in size, aquatic vertebrates use various means to ensure that their prey are less maneuverable than they. These include consumption of increasingly smaller prey relative to predator body size (culminating in filter feeding by the largest aquatic vertebrates); behaviors to concentrate, disturb, and disorient prey; and ambushing or suction feeding that avoid whole-body acceleration. Advantages of warm muscles are seen in the ability of endotherms to take more maneuverable prey than can ectotherms of the same size. Young stages of large aquatic vertebrates could be especially vulnerable to predators; viviparity or spawning in productive patches provides for rapid growth through vulnerable stages.
\end{abstract}

All organisms must function within limits imposed by laws that describe the properties and interactions of matter (Daniel and Webb 1987). These restrict the range of options for form and function as animal performance approaches the boundaries set by physical laws. Thus, physical principles can be used to predict and test ideas, leading to fuller understanding of the biology of organisms (Bartholomew 1987; Daniel and Webb 1987; Webb 1988). We apply this approach to consider the consequences of large size for locomotor capabilities of aquatic vertebrates. We first discuss mechanical concepts and forces acting on swimmers. These set constraints on function, of which we consider maneuverability to be most important. We then explore the implications of these constraints for aquatic vertebrates in terms of muscle temperature regulation, morphology and anatomy, predator-prey interactions, foraging patterns, and life history.

\section{Locomotor Forces}

Aquatic vertebrates use the tail and other appendages to swim. These propulsors generate thrust that equals the total resistance of the body and appendages at every instant. Both thrust and resistance arise from transfers of momentum between the animal and the water. These transfers are described in terms of a small set of mechanisms: friction drag, pressure drag, lift, and acceleration reaction (Daniel and Webb 1987; Webb 1988).

Friction or viscous drag arises from velocity gradients in which viscosity resists the relative motion of adjacent waier molecules. For vertebrates, large velocity gradients and viscous forces typically occur in a thin layer - the boundary layer-on body and propulsor surfaces. The viscous force is proportional to surface area and to the square of speed.

Pressure drag occurs because the flow pattern differs upstream and downstream of a solid object such as a vertebrate body or a flat surface that moves like an oar with the incident flow normal to the surface. The boundary layer eventually separates from the surface of most vertebrate-sized objects and creates a wake downstream. The pressure in the wake is lower than the pressure upstream, and the resulting pressure difference re- 
tards forward motion. Streamlining delays separation of the boundary layer from body until it is close to the downstream (trailing) tip of a body, and hence minimizes pressure drag. Conversely, an oar ensures that separation occurs early, which maximizes pressure drag. In either situation, pressure drag is proportional to surface area and the square of speed.

Lif, the force generated by a wing, also arises from a pressure difference between opposite surfaces of an object. In this case, the object moves at a small angle to the incident flow, and the boundary layer separates from the surface only close to the trailing edge. Water is accelerated over one surface, resulting in a lower pressure than on the other surface. The pressure difference (lift) is oriented approximately normal to the incident flow, and its magnitude is proportional to surface area and the square of speed.

Acceleration of an object dissipates energy by inducing acceleration of the water in the vicinity of the body. This energy can be visualized as a resistance increment, the acceleration reaction, equated to that of an added mass of water accelerated with the object. Acceleration resistance is hence proportional to acceleration rate and mass.

Several classifications of these forces are in common use, linking forces in terms of shared variables that affect their respective magnitudes. Acceleration reaction is proportional to mass, and hence volume, so it also is called a volume force. It is also proportional to acceleration, or the rate of change of velocity with time. Therefore, acceleration reaction is defined as an unsteady force. Drag and lift are proportional to the surface area of an object and are called surface forces. In addition, they are functions of speed, so they also are called steady forces.

Animals may employ drag, lif, and acceleration reaction to generate thrust. Each of these forces may also contribute to resistance, although lift probably is used as a resistance force only during braking (see Daniel and Webb 1987; Webb 1988).

The magnitude and relative importance of these forces vary with flow conditions. When an animal swims well below the water/air surface, flow conditions are related to reduced frequency $(\sigma)$ and Reynolds number $(R e)$. Reduced frequency indicates the extent to which oscillations of an object, such as a propuisor, affect the flow of a fluid passing over that object. Reynolds number indicates the relative importance of pressure drag, lift, and acceleration reaction compared to viscous forces. These terms are formally defined as

$$
\sigma=\omega L / u
$$

and

$$
R e=L u / \nu
$$

$L=$ characteristic length, usually total length;

$u=$ velocity;

$\nu=$ kinematic viscosity of water;

$\omega=$ radian frequency, $\pi f$

$f=$ oscillation frequency.

The Reynolds number for large vertebrates typically exceeds $10^{5}$. As a result, drag, lift, and acceleration reaction are the dominant forces acting on the body and propulsors. The relative importance of the steady and unsteady force components is estimated by $\sigma$. When an object oscillates many times during the time a particle of water traverses the object's length, or chord, that water particle is accelerated and decelerated during its passage. Then $\sigma$ is large and acceleration reaction forces are large. Hydromechanical analyses (Lighthill 1975; Daniel 1984) show this occurs when $\sigma$ exceeds 0.4 . Conversely, if an object oscillates slowly, so that a particle of water traversing the chord is not accelerated much from its path, $\sigma$ is small and the steady forces dominate. This occurs when $\sigma$ is less than 0.1. Both steady and unsteady force components should be taken into account for $0.1<\sigma<0.4$ (Daniel and Webb 1987).

For propulsors, $\sigma$ decreases with increasing animal size. Thus $f$ for oscillating propulsors is proportional to $L^{-0.45}$ to $L^{-1}$ (Peters 1983; Calder 1984; Heglund and Taylor 1988). As a result, $\sigma$ approaches 0.1 for propulsors of large vertebrates (Daniel and Webb 1987). Steady forces also become larger relative to unsteady forces as amplitude increases. The amplitudes of propulsor motions increase roughly with $L$ (Peters 1983), which further increases the importance of steady forces for propulsors of larger organisms.

The body does not oscillate as much as the tail, and tuna-shaped vertebrates can be visualized as a propulsor attached to a more-or-less rigid body (Lighthill 1977). Then $\sigma$ for the body is very much smaller than 0.1 .

Thus drag and lift are expected to be increasingly important for thrust and resistance as aquatic vertebrates increase in size because $R e$ is high and $\sigma$ becomes small. Acceleration reaction will still have an effect, mainly for the propulsors of medium-sized vertebrates (Daniel and Webb 1987), but energy expended in overcoming these forces more commonly contributes to energy 
wastage and low efficiency (Daniel and Webb 1987; Webb 1988).

Drag is the major resistance component for large and medium-sized vertebrates. It is well known that drag is reduced for streamlined shapes, which are typical of pelagic fishes (Webb 1975). In addition, larger aquatic vertebrates such as tunas (Thunnidae), swordfishes (Xiphidae), billfishes (Istiophoridae), dolphins, porpoises and whales (Cetacea; Mammalia), and extinct ichthyosaurs have similar body forms characteristic of manufactured vehicles optimally streamlined for minimum drag (Lighthill 1975).

Lift or drag might be used for propulsion. For a given propulsor moving at a given speed, lift is typically at least twice as great as drag at small $\sigma$ (Hoerner 1965, 1975; Blake 1983), although the advantage is reduced at large $\sigma$ (Lighthill 1975). Propulsors using drag, such as oars, only generate thrust about half the time, because a recovery stroke is necessary and drag during the recovery stroke increases total resistance. Propulsors using lift, such as wing-like hydrofoils, can generate thrust almost continuously. Therefore, propulsors using lift can be at least twice as effective in generating thrust as propulsors using drag, and may be up to five times more effective (Weihs 1989).

\section{Propulsor Design}

For swimming at constant speed (steady swimming in cruising and sprinting), surface forces become more important in thrust and resistance as animals increase in size. These forces vary with animal size in similar ways. However, animals must also accelerate to reach speed and to turn. When acceleration is great, resistance is dominated by acceleration reaction and body inertia; that is, resistance is proportional to mass or volume. However, because thrust is likely to depend on surface forces, acceleration performance of isometrically similar animals must decline in proportion to $L^{-1}$ with increasing animal size. In order to offset this trend, propulsors should be used that can generate the highest thrust, and these are hydrofoils (Weihs 1989). Therefore, hydrofoils should be increasingly common among larger vertebrates.

Design requirements for efficient hydrofoils are well known and easily identified. Hydrofoils beat across the path along which an animal moves. The tip-to-tip distance, called the span, is large. The length of the hydrofoil measured in the direction of the flow, called the chord, is small. The ratio of span to chord is defined as the aspect ratio.
Large aspect ratio and tapering of a hydrofoil towards the tips reduce one component of drag, the induced drag, which is a cost of generating lift. Tapering also reduces unwanted acceleration reaction forces of oscillating hydrofoils. Hydrofoils are typically rigid and curved (cambered) in cross section (see Felts 1966; Lighthill 1969; Webb 1975; Magnuson 1978; Blake 1983.)

Hydrofoils designed for high thrust and low resistance occur on tunas, swordfishes, billfishes, cetaceans, and extinct ichthyosaurs, all of which have similar external forms and range in length from $0.5 \mathrm{~m}$ to more than $30 \mathrm{~m}$. Such hydrofoils are also found among other extant and extinct vertebrates such as large marine turtles ( $<2 \mathrm{~m}$ long; Walker 1971; Davenport et al. 1984), plesiosaurs (the two pairs of flippers on bodies 14-15 m long; Walker 1971; Alexander 1975; Robinson 1975), and seals (Phocidae; $>2 \mathrm{~m}$ long; Fish et al. 1988). The appendages of the extinct pelagic marine Thalattosuchia (Crocodilia; >4 m long; Carroll 1985) probably were efficient hydrofoils as well. Other vertebrates such as the dolphin fish Coryphaena hippurus (Coryphaenidae; $<1.5 \mathrm{~m}$ ) and smaller vertebrates such as mackerel (Scombridae; Nelson 1976) and larval tuna (Webb and Weihs 1986) have fins with a few features of good hydrofoils. Hydrofoils, especially hydrofoils of advanced design, however, are characteristic of larger swimmers.

There are exceptions. The propulsors of manatees (Sirenia) and many extinct early marine reptiles and mammals appear poorly designed for efficient generation of lift. However, manatees are sluggish swimmers that graze on macrophytes and have few predators other than humans. Hence, manatees historically had little need for powerful swimming (Domning 1976; Marsh et al. 1978; Reynolds 1981; Irvine 1983). The elongate tails of early ichthyosaurs (Alexander 1975; Reiss 1986) and archeocetes (Gaskin 1982) presumably were sufficient for initial exploitation of aquatic resources. The long tail might have been held at an angle to the body to act like a hydrofoil, a possibility suggested by recent observations of submerged swimming snakes (Graham et al. 1987). However, these elongate-tail forms were quickly replaced by vertebrates with better hydrofoils.

\section{Locomotor Performance of Large Aquatic Vertebrates}

The propulsors generate thrust that must equal total resistance at every instant. Depending on the magnitude of the thrust, an animal may swim at 
constant speed, accelerate, or turn. Therefore, swimming performance is commonly measured in terms of speed and acceleration (Daniel and Webb 1987).

\section{Speed}

There are few accurate data on swimming speeds of vertebrates larger than about $0.5 \mathrm{~m}$ long (Wardle 1977; Beamish 1978). Maximum sprint speeds, lasting at most for a few seconds, appear to increase with $L^{0.4}$ to $L^{0.6}$ (Bainbridge 1961; Wardle 1975; Somero and Childress 1980; Wardle and Videler 1980; Videler 1981).

Cruising speeds also appear to increase with size, at least up to a length of about $1 \mathrm{~m}$ (Wardle 1977; Magnuson 1978). However, Wardle (1977) suggested that cruising speed may be limited for larger vertebrates by increases in drag that occur when the flow in the boundary layer changes from orderly laminar flow to turbulent flow. Associated Reynolds numbers are about $10^{5}$ to $10^{6}$, and Wardle (1977) suggested that cruising speeds of large fish follow Reynolds numbers at which the boundary layer transition occurs, with the result that cruising speed decreases with increasing size.

\section{Acceleration}

Less is known about acceleration rates of animals, especially large animals, than about speed. Accelerations cause animals to speed up or to turn - that is, to maneuver. Two types of acceleration are important: linear acceleration and centripetal acceleration, the latter causing animals to turn. Tums are especially important in maneuvers. Animals with good maneuverability can turn in small-radius circles, and agile maneuverers can do so at high rates. The force $(F)$ needed to turn is

$$
F=\text { mass } \times \text { speed }^{2} / \text { turning radius. }
$$

Therefore, maneuvering generally requires thrust forces proportional to an organism's mass and agile maneuvers also must be able to generate very high propulsion forces.

In the absence of comprehensive data, relationships between acceleration and size are deduced from theoretical models that equate thrust and resistance during acceleration; the model results are supported by a few observations (Daniel and Webb 1987). These analyses show that the relationship between acceleration rate and size should be $n$-shaped. The shape of the curve has been verified for shrimp (Daniel and Webb 1987; Daniel and Meyhöfer 1989). Fish 0.15 to $0.4 \mathrm{~m}$ long appear to fall on the flat portion of the $n$-shaped curve. Larger vertebrates should fall on the descending portion, when, as noted above, acceleration performance would be expected to vary with $L^{-1}$.

Therefore, maneuverability and agility are expected to decline as swimmers increase in size (Webb and Keyes 1981; Daniel and Webb 1987). However, this trend can be ameliorated if speed is increased. Howland (1974) discussed the relationship between maneuverability (measured as turning radius) and speed for animals propelled by surface forces such as the lift generated by hydrofoils. His analysis cast the problem in terms of the relationship between relative speed and maneuverability and the outcome of interactions between predators and their prey. He showed that a predator using hydrofoils could out-maneuver geometrically similar prey when

$$
v<r^{-0.5}
$$

$v=$ relative speed (prey speed/predator speed);

$r=$ relative turning radius or relative maneuverability (prey minimum turning radius/ predator minimum turning radius).

Thus, increased speed can increase maneuverability. There is a modest increase in maximum sprint speed with increased size that would help offset the expected decrease in maneuverability (Somero and Childress 1980).

\section{Ectothermy and Warm Muscles}

The ability to regulate body temperature with internally generated heat (endothermy) has had major effects on the evolution and ecology of many animal groups (Bennett 1980). In particular, endothermy results in an order-of-magnitude increase in the rate at which energy can be made available for various activities including enhanced locomotor performance and endurance (Bennett 1980). The largest aquatic vertebrates are mammals, and hence endotherms, as are many of intermediate-sized dolphins and porpoises. Several groups of fish (Thunnidae, Xiphidae, Istiophoridae, Lamnidae) also retain heat produced in certain tissues and regulate the temperature of these tissues (Graham 1983). The tunas and lamnid sharks regulate muscle temperatures, and this is associated with higher cruising and sprint speeds that are greater than those of ectotherms, as well as with high growth rates (Wardle 1977; Beamish 1978; Magnuson 1978; Feder 1987). Post-Triassic ichthyosaurs (e.g., Ichthyosaurus sp. and Stenopterygrus sp.) were probably also warm-bodied with 
high sustained growth and high rates of energy processing, as suggested by their bone histology (Buffrénil and Mazin, in press). Among the effects of muscle warming is an ability of muscle to contract more rapidly, which is believed to result in higher speeds (Brill 1978).

Schmidt-Nielsen (1979) pointed out that the standard physiological vocabulary is not satisfactory to accommodate the diversity of heat-regulation phenomena among organisms. We will use the term "warm muscled" to emphasize the connection between controlled muscle temperatures and increased swimming speed.

\section{Size Ranges of Aquatic Vertebrates}

Aquatic vertebrates range in size from fish larvae ( $\left.\geq 3 \times 10^{-3} \mathrm{~m} ; \geq 10^{-8} \mathrm{~kg}\right)$ to the blue whale Balaenoptera musculus ( $>30 \mathrm{~m}$ long; $>10^{5} \mathrm{~kg}$ ). We use various mechanical design features that would minimize drag and maximize lift, as well as the occurrence of warm muscles, to identify four categories of aquatic vertebrates in three size classes.

We initially recognize that the largest aquatic vertebrates, found among the cetacea, have many characteristics that are shared with many of the largest teleosts and elasmobranchs. These include a streamlined body shape, flukes and fins that function as hydrofoils, and warm muscle. Seals, too, show convergence with these characters (Fish et al. 1988). Lindsey (1978) defined vertebrates that share these characters as "thunniform," after the tunas (Thunnidae). Thunniform animals span a size range from about $0.5 \mathrm{~m}$ (frigate tuna Auxis thazard) to more than $30 \mathrm{~m}$ (blue whale). Numerous other vertebrates within this size range have one or more thunniform characteristics. Hydrofoils occur on plesiosaurs and some species of ichthyosaurs up to 14-15 m long (Alexander 1975) and on leatherback turtles Dermochelys coriacea $(<2 \mathrm{~m})$. All these organisms had, or have, warm muscles (Graham 1983).

Other aquatic vertebrates, primarily fish, overlap the size range of thunniform vertebrates with warm muscles, but have no thunniform characteristics. Examples include (a) actinopterygian fishes such as the orfe (Leuciscus idus, Cyprinidae; $<1 \mathrm{~m}$ ), pikeperch (Stizostedion sp., Percidae; >1.3 m), pike (Esox sp., Esocidae; <1.5 m), cod (Gadus sp., Gadidae; <1.5 m), Atlantic halibut (Hippoglossus hippoglossus, Pleuronectiformes; $<3-4 \mathrm{~m}$ ), and wels (Silurus glanis, Siluridae; $<5 \mathrm{~m}$ ) (Nikolski 1961; Muus and Dahlstrom 1964; Scott and Crossman 1973; Maitland 1977); (b) elasmo- branchs such as finback sharks (Prosylliidae; 0.15 $1 \mathrm{~m}$ ), dogfish sharks (Squalidae; $0.3-0.9 \mathrm{~m}$ ), and catsharks (Scyliorhinidae; 0.3-1.6 m) (Nikolski 1961; Muus and Dahlstrom 1964; Stevens 1988); and (c) the coelacanth (Latimeria chalumnae; $<2$ $\mathrm{m}$; Fricke and Plante 1988). In addition, marine crocodiles may reach $4 \mathrm{~m}$ in length.

Swordfishes and billfishes $(<4.5 \mathrm{~m}$; Nelson 1976), and hammerhead sharks (Sphyrnidae; <3$5 \mathrm{~m}$; Nikolski 1961; Muus and Dahistrom 1964; Stevens 1988) also overlap the size range of thunniform vertebrates with warm muscles and have thunniform morphology, but do not have warm muscle (Lindsey 1978). The swordfishes and billfishes, however, have warm brains (Block 1987). These fish are considered further below.

The fewest general categories that we think encompass the major locomotor trends among larger aquatic vertebrates are (1) small ectotherms less than about 0.5-1 m long, (2) medium-sized ectotherms 1-4 m long. (3) medium-sized, warmmuscled aquatic vertebrates $1-4 \mathrm{~m}$ long, and (4) large warm-muscled aquatic vertebrates more than 4-5 m long. Medium-sized aquatic vertebrates are extremely diverse but they usually are thunniform if they have warm muscles; medium-sized ectotherms are less likely to be thunniform. We focus here on large and medium-sized aquatic vertebrates, especially thunniform vertebrates.

\section{Form, Performance, and Size of Aquatic Vertebrates}

Thunniform vertebrates are well known for their continuous swimming, which in part helps them to regulate position in the water column (Magnuson 1978), and for their extensive migrations (Sharp and Dizon 1978; Bonner 1980). Much research effort has been expended in analyzing body form associated with this activity, and thunniform vertebrates are generally considered to exemplify the ideal design for sustained high-speed swimming. However, acceleration performance will be more important when maneuverability and agility are essential (Weihs 1972, 1973; Andersson and Norberg 1981; Norberg and Rayner 1987). Most aquatic vertebrates have evolved from particulate-feeding carnivores whose ability to capture elusive prey was essential (Elliott et al. 1977; Webb 1986). The ability to out-maneuver predators or prey determines the outcome of predator-prey interactions, and probably competition encounters, two major processes that affect community structure and life history. Because size is expected to reduce maneuverability, selection for compensat- 
ing mechanisms would be expected to be especially strong as vertebrates increased in size. Therefore, rather than review adaptations for highspeed cruising, we focus on biological factors associated with unsteady motions of large and medium-sized vertebrates.

\section{Predator-Prey Relationships}

The mechanical principles suggest that increasing size is likely to reduce the maneuverability of aquatic invertebrates and hence impose performance limits for predator-prey interactions. Any consequences of reduced performance in predator-prey encounters for larger aquatic vertebrates will be exacerbated because larger organisms may need to capture more food items and hence to participate in predator-prey interactions more frequently. Food particle sizes eaten by fish typically average $0.07 L$ (Kerr 1974; Ware 1978). Piscivores tend to consume prey sized up to a third of the predator's length (Popova 1978), but more commonly $0.15 L$ to $0.20 L$ (Jude et al. 1987). Thus the size of food items eaten by small particulate-feeding fish increases with predator length (Kerr 1974; Ware 1978). However, ration requirements typically increase in parallel with metabolic rate $(M)$, in proportion to $M^{0.75}$ or $L^{2.25}$ (Peters 1983; Calder 1984). Therefore, the number of items consumed would be expected to increase with $L^{1.25}$.

In order to compensate for the theoretical expectation of decreasing forage performance. three types of behaviors would be expected to become more prevalent as vertebrates increase in size: selection of prey that is less likely to flee, counteraction of prey maneuverability advantages, and substitution of nonlocomotor foraging mechanisms for food capture.

\section{Food Selection}

As aquatic vertebrates increase in size, they tend to consume relatively smaller and hence relatively less elusive prey (equation 4). Fish such as pilchards, herring, mackerel, capelin, scad, and gobies, or their freshwater equivalents, and cephalopods are major diet items for the nonthunniform actinopterygians, elasmobranchs, and coelacanth listed earlier (see "Size Ranges of Aquatic Vertebrates"). These fish, ranging in length from about 0.3 to $5 \mathrm{~m}$, eat roughly similar-sized food, so that relative prey size declines with increasing predator size.

In addition, many larger nonthunniform fish, such as halibut, cod, and elasmobranchs consume increasing quantities of benthic prey (Nikolski
1961; Muus and Dahlstrom 1964; Scott and Crossman 1973; Matiland 1977). These prey rely on camouflage and burying themselves rather than on maneuverability to avoid predators, and predator maneuverability and agility are less critical to prey capture (Figure 1).

The trend towards selection of relatively smaller and less maneuverable prey is more clearly shown over the larger size range of thunnifrom vertebrates. Active, elusive, pelagic fish and cephalopods are the major prey of smaller thunniform vertebrates with warm muscles such as frigate tuna ( $<0.5 \mathrm{~m}$ ), bluefin tuna (Thunnus thynnus; $<4 \mathrm{~m}$ ), small mackerel sharks (Lamnidae; $<4 \mathrm{~m}$ ), ichthyosaurs $(<3 \mathrm{~m}$ ), small dolphins (Delphinidae; $<4 \mathrm{~m}$ ), and porpoises (Phocoenidae; $2.5 \mathrm{~m}$ ) (Sharp and Dizon 1978; Bonner 1980; Gaskin 1982; Stevens 1988 ). These prey items are also eaten by the largest vertebrates, over an order of magnitude longer; e.g. great white shark (Carcharodon carcharias; Lamnidae; 6-11 m), ichthyosaurs (<15 $\mathrm{m}$ ), plesiosaurs (14 m) (Alexander 1975), killer whales (Orcinus orca; Delphinidae; 9-11 m), sperm whales (Physeter catodon; Physeteridae; $<19 \mathrm{~m}$ ). and blue whales (>30 m) (Bonner 1980; Gaskin 1982). Many of these vertebrates opportunistically take larger prey such as small sharks, rays, marine birds, and marine mammals (Bonner 1980; Gaskin 1982). Nevertheless, because food items of roughly the same size are taken by predators with a wide range of lengths, it again follows that food item size for thunniform vertebrates decreases in relative size, from approximately $10^{-1}$ to $10^{-2}$ of predator length $\left(10^{-1}\right.$ to $10^{-3}$ of predator mass).

The largest thunniform vertebrates-the elasmobranch families Megachasmidae $(<5 \mathrm{~m})$ and Cetorhinidae and Rhiniodontidae (10-18 m); the mysticete cetacean families Balaenidae $(<20 \mathrm{~m})$ and Balaenopteridae (>30 m) - filter-feed on concentrated prey, including fish schools (Bonner 1980; Gaskin 1982; Horwood 1987; Stevens 1988). Then, food items may be $10^{-3}$ of predator length (10-8 of predator mass; Weihs and Webb 1983).

These general trends for increasingly larger predators to take prey decreasing in relative size promote prey capture by reducing prey maneuverability relative to predator maneuverability (see equation 4). This trend culminates in filter feeding wherein individual prey items are neither sensed nor seized and consumption occurs with no regard to the evasive performance of prey. The influence of prey maneuverability on the selection of particulate- or filter-feeding behavior is illustrated by 


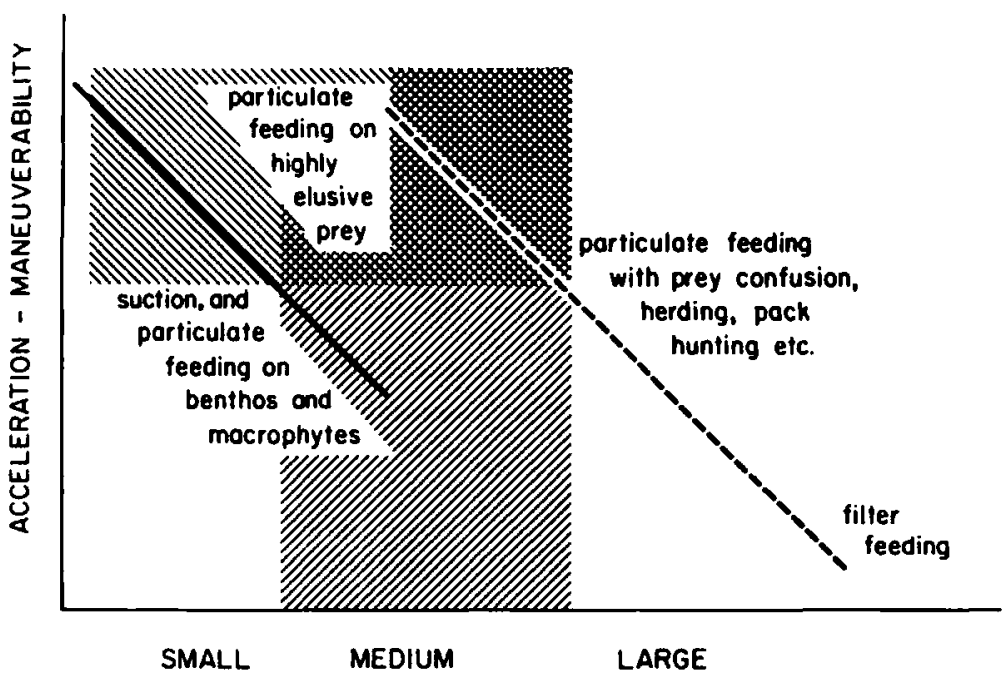

FIGURE 1.-Diagrammatic summary of trends in acceleration and maneuverability in relation to size for foraging aquatic animals. Ectothermic animals (solid line) tend to shift from particulate feeding on elusive prey to feeding on less elusive benthic prey or large plants and to ambushing and suction-feeding to avoid whole-body accelerations. Warm-bodied vertebrates (broken line) control muscle temperature. This is postulated to provide locomotor power that allows smaller warm-muscled fish to maneuver and feed like small ectotherms; larger warm-bodied vertebrates tend to emphasize behaviors such as filter feeding that negate prey maneuverability. None of these behaviors are exclusive to large aquatic vertebrates, but they become the dominant feeding patterns as size increases.

fish that perform both behaviors. Among tunas, larger fish prey (higher relative maneuverability) are taken as particles, whereas smaller fish prey (lower relative maneuverability) may be filtered (Sharp and Dizon 1978).

It should be noted that a component of the asymmetry in relative maneuverability arises because the predator's mouth increases in size relative to the distance a given prey item can traverse in unit time. Thus, declining prey speed and maneuverability relative to the predator and a larger predator mouth combine to reduce the probability that prey can escape from a predator's attack trajectory (Webb and Corolla 1981).

\section{Behaviors Reducing Relative Maneuverability}

Large aquatic vertebrates, many medium-sized thunniform vertebrates, and a few larger nonthunniform vertebrates further reduce the discrepancy between prey and predator maneuverabilities by concentrating, disturbing, or disorienting prey. This is often a cooperative activity of predator groups. Thus, tuna have been described as swimming and feeding in a crescent formation that tends to herd and concentrate prey (Partridge 1982), although it is not clear if such behavior is a general phenomenon. Many small and mediumsized cetaceans hunt in packs and use bottom to- pography, bubble nets, and other means to concentrate prey (Bonner 1980; Gaskin 1982; Wursig 1986, 1988; Orton and Brodie 1987; HeimlichBoran 1988).

Predators may disturb and disorient naturally schooling or concentrated prey for easier capture by "thrashing about" among the prey and taking stunned and injured individuals (some tunas $>1$ $\mathrm{m}$; swordfishes and billfishes $<4.5 \mathrm{~m}$ ) (Bonner 1980; Gaskin 1982; Stevens 1988). Large sharks, whales, and perhaps tunas may treat a prey school, or part of the school, as the food unit, this unit being much less maneuverable than the individual members (Sharp and Dizon 1978; Bonner 1980; Gaskin 1982; Stevens 1988). This behavior culminates in filter feeding.

\section{Nonlocomotor Foraging Mechanisms for Food Capture}

Many actinopterygian fishes use suction instead of whole-body acceleration to ambush and capture prey. This is presumably the method used by medium-sized ectothermic fish, such as groupers (Epinephelus sp., Serranidae; $<3.5 \mathrm{~m}$ ) that feed in the water column. Some large vertebrates also avoid whole-body accelerations but do not use suction. Sperm whales, the largest toothed whales, appear to hover at depth in the vicinity of squid 
schools where prey capture requires little more than opening the mouth; lures may also be used (Gaskin 1982). Alexander (1975) postulated that plesiosaurs used their long necks to strike at prey, again obviating the need for whole-body acceleration and maneuverability. Feeding penguins and sea lions (Otariidae) make analogous use of their necks.

\section{Warm Muscles}

Warm muscles convey the ability to swim at higher speeds, when lift forces for powering maneuvers are also increased (equation 4). The resultant improvement in maneuverability compared to that expected in the absence of superior swimming speed is seen in prey selection by medium-sized thunniforms, whose feeding behavior is often reminiscent of that of small piscivores (Magnuson and Heitz 1971). These thunniform vertebrates successfully pursue elusive prey whereas equivalent-sized ectotherms use suction or forage more on benthic resources as described above (Figure 1).

\section{Reproductive Biology}

The body morphology of adults of large aquatic vertebrates favors cruising and sprinting. It is less effective for avoiding predators than morphologies that use acceleration reaction, a volume force, to overcome the inertia, which is also proportional to volume (Webb 1986). Large adult size is a major protection against predation; most large aquatic vertebrates have little to fear from predators other than killer whales and humans. However, a major problem for all sexually reproducing animals is surviving while growing from an egg $(<1$ $\mathrm{mm}$ ) to an adult that may be eight orders of magnitude larger (Werner, in press). Werner (in press) pointed out that large size is usually achieved via a series of stages, each adapted to a particular habitat in terms of maximizing some function of survival and growth. The stages are linked by ontogenetic niche shifts, sometimes accompanied by dramatic metamorphosis. Furthermore, the larger the adult size, the larger the number of intermediate stages that might be expected.

Larval and juvenile stages with the same morphology as their large vertebrate parents could be vulnerable to predation (Webb 1986). This predation risk is reduced by viviparity in most extant medium-sized vertebrates with warm muscle as well as in large aquatic vertebrates, including extinct ichthyosaurs (Nikolski 1961; Breder and Rosen 1966; Romer 1966). Mammals provide exten- sive postpartum parental care, and the tendency of young sharks to follow adults would provide some postpartum parental protection (Breder and Rosen 1966).

In contrast, actinopterygian fishes are oviparous. Thunnids produce numerous pelagic eggs with diameters of the order of $1 \mathrm{~mm}$. They spawn in warm waters, when time to hatching and first feeding is short (Breder and Rosen 1966; Magnuson and Heitz 1977; Hunter 1981). Scombrid larvae have large mouths to take relatively large food items; they shift to fish prey when $5-10 \mathrm{~mm}$ long and are persistent attackers (Hunter and Kimbrell 1980; Hunter 1981). These larvae have a relatively large finfold (Fritzsche 1978; Hunter 1981), but develop a cruising form early in their life (Webb and Weihs 1986). As a result, they tend to swim faster than other fish larvae (Hunter 1972, 1981). All these factors ensure very rapid growth through the most vulnerable stages; tuna can reach a mass of $3 \mathrm{~kg}(0.5 \mathrm{~m})$ in their first year (Rivas 1978).

Basking sharks (Cetorhinidae) are also oviparous, but the egg case is large $(0.3 \mathrm{~m})$. This undoubtedly offers some protection from predation until the young begin a free-living existence at a relatively large size.

\section{Resistance Reduction}

Numerous mechanisms to reduce drag on large and medium-sized thunniforms have been studied in detail and reviewed regularly (see Bone 1974; Webb 1975; Magnuson 1978; Blake 1983). Because, we suggest, acceleration performance is also important in the locomotor repertoire of these animals, acceleration resistance-reducing mechanisms should be expected. These should be sought among medium-sized animals. Mechanisms that reduce acceleration resistance would be less likely among the largest vertebrates because their prey choices, culminating in filter feeding, negate the need for high maneuverability.

One mechanism for reducing acceleration resistance-reduction of body inertia (Webb and Skadsen 1979)-is used by mammalian dolphins (Buffrénil et al. 1985; Buffrénil and Schoevaert 1988). The relative mass of the dolphin skeleton (skeletal mass/body mass) is reduced by $40-50 \%$ compared to that of terrestrial mammals of similar size. For comparable amounts of muscle driving the body, this reduces total body mass by $5-7 \%$, and would translate into a 5-7\% increase in acceleration rate or a $5-7 \%$ reduction in turning radius. The bone structure of ichthyosaurs is strongly reminiscent 
of that of delphinids (Ricqlés 1976; Buffrénil and Mazin 1989), implying that they too may have reduced skeletal mass (Buffrénil et al. 1987). Reduction in overall skeletal mass is less essential for larger vertebrates, and measurements on larger cetaceans, although crude, indicate no reduction (Nishiwaki 1950; Omura 1950; Fujino 1955; Lockyer 1976). This also shows that mass reduction in delphinids cannot be dismissed as an adaptation for buoyancy regulation.

\section{Discussion}

Our view of the locomotor biology of aquatic vertebrates follows from theoretical expectations of a decline in acceleration performance as body size increases. We suggest that this is one proximal causal mechanism underlying many features of the biology of thunniform vertebrates. In addition, compensation for declining acceleration performance may have been more important in the evolution of large size among swimmers than the highspeed cruising that is the hallmark of modern thunniforms. We make this suggestion because thunniform vertebrates appear to have nearshore origins where cruising performance and long migrations are less likely to be essential. Tunas are believed to be derived from nearshore fishes (Sharp and Pirages 1978), for example, and ichthyosaurs and cetaceans are derived from terrestrial fauna (Romer 1966). Large primitive representatives of these latter groups (and the modern manatee) had forms that were hydrodynamically poor for steady swimming (Romer 1966). In addition, some amphibians achieved large size, but only elongate forms have been found. For example, extinct aquatic stegocephalian amphibians reached lengths in excess of $2 \mathrm{~m}$; the skull alone of Mastodonsaurus sp. may be $1.25 \mathrm{~m}$ long (Piveteau and Deschaseaux 1955). Therefore, the specializations that define the thunniform vertebrates are not essential for aquatic vertebrates to become large. Nevertheless, subsequent increases in steady swimming capability would improve maneuverability, offsetting declines otherwise expected with increasing size and increasing competitive abilities for local resources.

Irrespective of the causal factors leading to the thunniform design, the numerous shared features of thunniform vertebrates from several vertebrate lineages suggest that this general design is the best solution to large size, given available habitat, for aquatic vertebrates. The rapid radiation of thunniform vertebrates into pelagic habitats was undoubtedly facilitated by increased steady swim- ming performance associated with thunniform characteristics.

The general principle that acceleration capabilities decline for larger animals appears to apply in all major environments. The size limit for powered flight by birds is well known to result from the decreasing ability of lift, a surface force, to support body mass against gravitational acceleration (Pennycuick 1972). Andersson and Norberg (1981) and Norberg and Rayner (1987) argued that maneuverability is similarly reduced with increasing size among birds and bats. These authors also described a tendency for larger birds and bats to take relatively less maneuverable prey, analogous to diet trends in aquatic vertebrates. Similarly, large terrestrial animals such as elephants do not use gaits associated with large body accelerations (McMahon and Bonner 1983).

Although locomotion plays an important role in the lives of animals and principles of locomotor mechanics appear to underlie some major biological trends in aquatic vertebrates, the principles will not explain all features of the biology of size. The mechanical principles discussed here will only become limiting at high performance levels; low performance makes little or no demand on sophisticated design (Roughgarden and Diamond 1986), as shown by manatees. In addition, mechanical principles can only be used to analyze and predict performance capabilities, whereas animal habitat and life history are affected by many other factors, especially interactions with other organisms (Chesson and Case 1986). Finally, present-day morphology must have arisen from selection in historical environments (Feder 1987). Thus an animal with a particular morphology may not be restricted to one activity pattern, and it may rarely or never perform at the limits permitted by a given design. As a result, many organisms may appear to be exceptions. For example, tuna feeding habits are diverse. Some tunas are benthic feeders, analogous to medium-sized ectotherms.

Nevertheless, increasing size is one factor that limits performance; hence a premium is likely to be placed on selection of mechanisms that maximize swimming performance as animals become large. These mechanisms include propulsors that provide high thrust, body shapes that minimize drag, and behaviors that reduce the need for acceleration. This is illustrated by various trends in foraging behavior. Some options are excluded for the largest vertebrates, which reduces the diversity of their behavior, but smaller vertebrates are not so constrained. Again, feeding patterns of tunas 
and small ectotherms are diverse compared to those of large vertebrates.

The trends discussed here are based on very large size ranges. Do they apply over small size ranges, perhaps that of tunas? What about exceptions? In theory, the trends must apply over any size range of animals that function at the limits imposed by physical principles. As noted above, animals often do not have to function at these limits so that variety (exceptions) occurs, and even may be common. Furthermore, animals show many behavioral adaptations to bypass apparent limits (Bartholomew 1987), such as foraging behaviors described above. Nevertheless, animals must function within physical and chemical laws. Such principles can lead to unequivocal statements of expectation. This can lead to identification of apparent "misfits" and exceptions, each of which represents an adaptive solution to an apparently limiting situation specified by a model. Therefore, misfits arise from simplification inevitable in any model. However, models are usually constructed to guide, and it is important to test them against "misfits" to reveal new principles or identify more significant factors than those presumed by the models.

Thus billfishes and swordfishes are thunniform in all but warm muscles. The difference seems to be associated with a greater emphasis on prey disruption and injury. Is this behavioral difference sufficient explanation for the partial convergence of these fish with true thunniform animals? Dolphin fishes also have some thunniform characteristics, but are less streamlined and do not have warm muscles. They have a large dorsal fin that is erected for maneuvers (Webb and Keyes 1981). But what exactly does the ocean sunfish do (Mola mola; $<3.5 \mathrm{~m})$ ? How do hammerhead sharks forage? More accurate data and observations on many larger vertebrates are essential if their biology and ecological role are to be known, and, of course, if appropriate harvesting strategies are to be planned. A formal physical framework is essential for framing these observations, of which we present one example. Without such a framework, and appropriate data, our understanding of these organisms will continue to rest too heavily on speculation.

\section{Acknowledgments}

This contribution is dedicated to F. E. J. Fry, who was a major influence in encouraging a broad view of animal-environment interactions, and in trying to take an animal's view of its world. We thank R. W. Brill, D. M. Lavigne, J. J. Magnuson, and E. D. Stevens for their constructive comments, but recognize that they still will not agree with all we suggest. This work was completed while P.W.W. was on sabbatical leave at the Ministry of Agriculture, Fisheries and Food, Fisheries Laboratory, Lowestoft. We thank G. P. Amold for his hospitality. Funding was provided by the National Science Foundation, Regulatory Biology Program, grant DCB-8701923.

\section{References}

Alexander, R. M. 1975. The chordates. Cambridge University Press, Cambridge, UK.

Andersson, M., and R. A. Norberg. 1981. Evolution of reversed sexual size dimorphism and role partitioning among predatory birds with a size scaling of flight performance. Biological Journal of the Linnean Society 15:105-130.

Bainbridge, R. 1961. Problems of fish locomotion. Symposium of the Zoological Society of London 5: 13-32.

Bartholomew, G. A. 1987. Interspecific comparisons as a tool for ecological physiologists. Pages 11-37 in M. E. Feder, A. F. Bennett, W. W. Burggren, and R. B. Huey, editors. New directions in ecological physiology. Cambridge University Press, New York.

Beamish, F. W. H. 1978. Swimming capacity. Pages 101-187 in W. S. Hoar and D. J. Randall, editors. Fish physiology, volume 7. Academic Press, New York.

Bennett, A. F. 1980. The metabolic foundations of vertebrate behavior. BioScience 30:452-456.

Blake, R. W. 1983. Fish locomotion. Cambridge University Press, Cambridge, UK.

Block, B. A. 1987. Strategies for regulating brain and eye temperatures: a thermogenic tissue in fish. Pages 401-420 in P. DeJours, L. Bolis, C. R. Taylor and E. R. Weibel, editors. Comparative physiology: life in water and on land. Liviana Press, New York.

Bone, Q. 1974. Muscular and energetic aspects of fish swimming. Pages 493-528 in T. Y. Wu, C. J. Brokaw and C. Brennan, editors. Swimming and flying in nature. Plenum, New York.

Bonner, W. N. 1980. Whales. Blandford Press, Poole, UK.

Breder, C. M., and D. E. Rosen. 1966. Modes of reproduction in fishes. American Museum of Natural History, Garden City, New York.

Brill, R. W. 1978. Temperature effects on speeds of muscle contraction and stasis metabolic rate. Pages 277-283 in G. D. Sharp and A. E. Dizon, editors. The physiological ecology of tunas. Academic Press, New York.

Buffrénil, V. de, A. Collet, and M. Pascal. 1985. Ontogenetic development of skeletal weight in a small delphinid, Delphinus delphis (Cetacea, Ondontoceii). Zoomorphology (Berlin) 105:336-344.

Buffrénil, V. de, and J.-M. Mazin. In press. Histological characteristics of periosteal cortices in the long bones of the ichthyosaurs: description and functional interpretation. Palaeobiology. 
Buffrénil, V. de, J.-M. Mazin, and A. de Ricqlés. 1987 Caracteres structuraux et mode de croissance du femur d'Omphalosaurus nisseri, ichtyosaurien du Trias Moyen du Spitzberg. Annales de Paleontology 73: 195-216.

Buffrénil, V. de, and D. Schoevaert. 1988. On how the periosteal bone of the delphinid humerous becomes cancellous: ontogeny of an historical specialization. Journal of Morphology 198:149-164.

Calder, W. A. 1984. Size, function, and life history. Harvard University Press, Cambridge, Massachusetts.

Carroll, R. L. 1985. Evolutionary constraints in aquatic diaspid reptiles. Special Papers in Palaeontology 33:145-155.

Chesson, P. L., and T. J. Case. 1986. Overview: nonequilibrium community theories: chance, variability, history, and coexistence. Pages 229-239 in J. Diamond and T. J. Case, editors. Community ecology. Harper and Row, New York.

Daniel, T. L. 1984. Unsteady aspects of aquatic locomotion. American Zoologist 24:121-134.

Daniel, T. L., and E. Meyhöfer. 1989. Size limits in escape locomotion of carridean shrimp. Journal of Experimental Biology 143:245-265.

Daniel, T. L., and P. W. Webb. 1987. Physical determinants of locomotion. Pages 343-369 in P. DeJours, L. Bolis, C. R. Taylor, and E. R. Weibel, editors. Comparative physiology: life in water and on land. Liviana Press, New York.

Davenpor, J., S. A. Munks, and P. J. Oxford. 1984. A comparison of the swimming of marine and freshwater turtles. Proceedings of the Royal Society of London, B Biological Sciences 220:447-475.

Domning, D. 1976. An ecological model for the late Tertiary sirenian evolution in the North Pacific Ocean. Systematic Zoology 25:352-362.

Elliott, J. P., I. McTaggart-Cowan, and C. S. Holling. 1977. Prey capture by the African lion. Canadian Journal of Zoology 55:1811-1828.

Feder, M. E. 1987. The analysis of physiological diversity: the prospects for pattern documentation and general questions in ecological physiology. Pages 3875 in M. E. Feder, A. F. Bennett, W. W. Burggren, and $R$. B. Huey, editors. New directions in ecological physiology. Cambridge University Press, New York.

Felts, W. J. L. 1966. Some functional and structural characteristics of cetacean flippers and flukes. Pages 255-276 in K. S. Norris, editor. Whales, dolphins and porpoises. University of California Press, Berkeley.

Fish, F. E., I. Innes, and K. Ronald. 1988. Kinematic and estimated thrust production of swimming harp and ringed seals. Journal of Experimental Biology 137:157-173.

Fricke, H., and R. Plante. 1988. Habitat requirements of the living coelacanth Latimeria chalumnae at Grande Comore, Indian Ocean. Naturwissenschaften 75:149-151.

Fritzsche, R. A. 1978. Development of fishes of the mid-Atlantic Bight, volume 5. Chaeotodontidae through Ophiidae. U.S. Fish and Wildlife Service Biological Services Program FWS/OBS-78/12.

Fujino, K. 1955. On the body weight of sei whales located in the adjacent waters of Japan. Scientific Report of the Whales Research Institute Tokyo 10: 133-139.

Gaskin, D. E. 1982. The ecology of whales and dolphins. Heinemann, London.

Graham, J. B. 1983. Heat transfer. Pages 248-279 in P. W. Webb and D. Weihs, editors. Fish biomechanics. Praeger, New York.

Graham, J. B., W. R. Lowell, 1. Rubinoff, and J. Motta. 1987. Surface and subsurface swimming of the sea snake Pelamis platurus. Journal of Experimental Biology 127:27-44.

Heglund, N. C., and C. R. Taylor. 1988. Speed, stride frequency and energy cost per stride: how do they change with body size and gait? Journal of Experimental Biology 138:301-318.

Heimlich-Boran, J. R. 1988. Behavioral ecology of killer whales (Orcinus orca) in the Pacific Northwest. Canadian Joumal of Zoology 66:565-578.

Hoerner, S. F. 1965. Fluid dynamic drag. Hoemer Fluid Dynamics, Brick Town, New Jersey.

Hoerner, S. F. 1975. Fluid dynamic lift. Hoerner Fluid Dynamics, Brick Town, New Jersey.

Horwood, J. 1987. The sei whale. Croom Helm, Beckenham, UK.

Howland, H. C. 1974. Optimal strategies for predator avoidance. The relative importance of speed and manoeuvrability. Journal of Theoretical Biology 47: 333-350.

Hunter, J. R. 1972. Swimming and feeding behavior of larval anchovy, Engraulis mordax. U.S. National Marine Fisheries Service Fishery Bulletin 70:821838.

Hunter, J. R. 1981. Feeding ecology and predation of marine fish larvae. Pages 33-77 in R. Lasker, editor. Marine fish larvae. University of Washington Press, Seattle.

Hunter, J. R., and C. A. Kimbrell. 1980. Early life history of Pacific mackerel, Scomber japonicus. U.S. National Marine Fisheries Service Fishery Bulletin 78:89-101.

Irvine, A. B. 1983. Manatee metabolism and its influence on distribution in Florida. Biological Conservation 25:315-334.

Jude, D. J., F. J. Tesar, S. F. Deboe, and T. Miller. 1987. Diet and selection of major prey species by Lake Michigan salmonines, 1973-1982. Transactions of the American Fisheries Society 116:677691.

Kerr, S. R. 1974. Theory of size distribution in ecological communities. Journal of the Fisheries Research Board of Canada 31:1859-1862.

Lighthill, M. J. 1969. Hydromechanics of aquatic animal propulsion: a survey. Annual Review of Fluid Mechanics 1:413-446.

Lighthill, M. J. 1975. Mathematical biofluiddynamics. Society for Industrial and Applied Mathematics, Philadelphia.

Lighthill, M. J. 1977. Mathematical theories of fish 
swimming. Pages 131-144 in J. H. Steele, editor. Fisheries mathematics. Academic Press, New York. Lindsey, C. C. 1978. Form, function, and locomotory habits. Pages 1-100 in W. S. Hoar and D. J. Randall, editors. Fish physiology, volume 7. Academic Press, New York.

Lockyer, C. 1976. Body weight of some species of large whales. Journal du Conseil, Conseil International pour l'Exploration de la Mer 36:259-273.

Magnuson, J. J. 1978. Locomotion by scombroid fishes: hydrodynamics, morphology and behavior. Pages 239-313 in W. S. Hoar and D. J. Randall, editors. Fish physiology, volume 7. Academic Press, New York.

Magnuson, J. J., and J. G. Heitz. 1971. Gill raker apparatus and food selectivity among mackerels, tunas, and dolphins. U.S. Fish and Wildlife Service Fishery Bulletin 69:361-370.

Maitland, P. S. 1977. Freshwater fishes of Britain and Europe. Hamlyn Publishing. London.

Marsh, H., A. V. Spain, and G. E. Heinsohn. 1978. Physiology of the dugong. Comparative Biochemistry and Physiology A, Comparative Physiology 61: 159-168.

McMahon, T. A., and J. T. Bonner. 1983. On size and life. Scientific American Library, New York.

Muus, B. J., and P. Dahlstrom. 1964. Sea fishes. Collins, Glasgow, UK.

Nelson, J. S. 1976. Fishes of the world. Wiley, New York.

Nikolski, G. V. 1961. Special ichthyology. Israel Program for Scientific Translations, Jerusalem. (U.S. Department of Commerce, Office of Technical Services, Washington, D.C.)

Nishiwaki, M. 1950. On the body weight of whales. Scientific Report of the Whales Research Institute Tokyo 4:1-19.

Norberg, U. M., and J. M. V. Rayner. 1987. Ecological morphology and flight in bats (Mammalia: Chiroptera): wing adaptations, flight performance, foraging strategy and echolocation. Philosophical Transactions of the Royal Society of London, B Biological Sciences 316:335-427.

Omura, H. 1950. On the body weight of sperm and sci whales located in the adjaccnt watcrs of Japan. Scientific Report of the Whales Research Institute Tokyo 4:1-19.

Orton, L. S., and P. F. Brodie. 1987. Engulfing mechanics of fin whales. Canadian Journal of Zoology 65:2898-2907.

Partridge, B. L. 1982. The structure and function of fish schools. Scientific American 247(6):114-123.

Pennycuick, C. J. 1972. Animal flight. Edward Arnold, London.

Peters, R. H. 1983. The ecological implications of body size. Cambridge University Press, Cambridge, UK.

Piveteau, J., and C. Deschaseaux. 1955. Stereospondyli. Pages 136-172 in J. Piveteau, editor. Traité de paleontologie, volume 5 . Masson et Cie, Paris.

Popova, O. A. 1978. The role of predacious fish in ecosystems. Pages 215-249 in S. D. Gerking, editor. Ecology of freshwater fish production. Blackwell Scientific Publications, Oxford, UK.
Reiss, J. 1986. Fortbewegunsweise, Schwimmbiophysik und Phylogenie der Ichthyosaurier. Palaeontographica Abteilung A, Palaeozoologie-Stratigraphie 192:93-155.

Reynolds, J. E. 1981. Behaviour pattern of the West Indian manatee, with emphasis on feeding and diving. Florida Scientist 44:233-242.

Ricqlés, A. de. 1976. On bone histology of fossil and living reptiles, with comments on its functional and evolutionary significance. Linnean Society Symposium Series 3:123-150.

Rivas, L. R. 1978. Preliminary models of annual life history cycles of the north Atlantic bluefin tuna. Pages 369-393 in G. D. Sharp and A. E. Dizon, editors. The physiological ecology of tunas. Academic Press, New York.

Robinson, J. A. 1975. The locomotion of plesiosaurs. Neues Jahrbuch für Geologie und Paläontologie 149: 286-332.

Romer, A. S. 1966. Vertebrate paleontology. University of Chicago Press, Chicago.

Roughgarden, J., and J. Diamond. 1986. Overview: the role of species interactions in community ecology. Pages 333-343 in J. Diamond and T. J. Case, editors. Community ecology. Harper and Row, New York.

Schmidt-Nielsen, K. 1979. Animal physiology. Cambridge University Press, New York.

Scott, W. B., and Crossman, E. J. 1973. Freshwater fishes of Canada. Fisheries Research Board of Canada Bulletin 184.

Sharp, G. D., and A. E. Dizon. 1978. The physiological ecology of tunas. Academic Press, New York.

Sharp, G. D., and S. W. Pirages. 1978. The distribution of red and white swimming muscles, their biochemistry, and the biochemical phylogeny of selected scombrid fishes. Pages 41-78 in G. D. Sharp and A. E. Dizon, editors. The physiological ecology of tunas. Academic Press, New York.

Somero, G. N., and J. J. Childress. 1980. A violation of the metabolism-size scaling paradigm: activities of glycolytic enzymes in muscle increase in largersize fish. Physiological Zoology 53:322-337.

Stevens, J. D. 1988. Sharks. Merehurst Press, London.

Videler, J. J. 1981. Swimming movements, body structure and propulsion in cod, Gadus morhua. Symposium of the Zoological Society of London 48:127.

Walker, W. F. 1971. Swimming in the turte family, Chelonidae. Copeia 1971:229-233.

Wardle, C. S. 1975. Limits to fish swimming speed. Nature (London) 225:725-727.

Wardle, C. S. 1977. Effect of size on swimming speeds of fish. Pages 299-313 in T. J. Pedley, editor. Scale effects in animal locomotion. Academic Press, New York.

Wardle, C. S., and J. J. Videler. 1980. Fish swimming. Pages 125-150 in H. Y. Elder and E. R. Trueman, editors. Aspects of animal movement. Cambridge University Press, Cambridge, UK.

Ware, D. M. 1978. Bioenergetics of pelagic fish: theoretical change in swimming speed and ration with 
body size. Journal of the Fisheries Research Board of Canada 35:220-228.

Webb, P. W. 1975. Hydrodynamics and energetics of fish propulsion. Fisheries Research Board of Canada Bulletin 190.

Webb, P. W. 1986. Locomotion and predator-prey relationships. Pages $24-41$ in $M$. E. Feder and G. V. Lauder, editors. Predator-prey relationships. University of Chicago Press, Chicago.

Webb, P. W. 1988. Simple physical principles and aquatic vertebrate locomotion. American Zoologist 28:709-725.

Webb, P. W., and R. T. Corolla. 1981. Burst swimming performance of northern anchovy, Engraulis mordax, larvae. U.S. National Marine Fisheries Service Fishery Bulletin 79:143-150.

Webb, P. W., and R. S. Keyes. 1981. Division of labor between median fins in swimming dolphin fish. Copeia 1981:901-904.

Webb, P. W., and J. M. Skadsen. 1979. Reduced skin mass: an adaptation for acceleration in some teleost fishes. Canadian Journal of Zoology 57:1570-1575.

Webb, P. W., and D. Weihs. 1986. Functional locomotor morphology of early life history stages of fishes. Transactions of the American Fisheries Society 115:115-127.
Weihs, D. 1972. A hydromechanical analysis of fish turning manoeuvres. Proceedings of the Royal Society of London, B Biological Sciences 182:59-72.

Weihs, D. 1973. The mechanism of rapid starting of slender fish. Biorheology 10:343-350.

Weihs, D. 1989. Design features and mechanics of axial locomotion in fish. American Zoologist 29:151160.

Weihs, D., and P. W. Webb. 1983. Optimization of locomotion. Pages 339-371 in P. W. Webb and D. Weihs, editors. Fish biomechanics. Praeger, New York.

Werner, E. E. In press. Size, scaling, and the evolution of complex life cycles. In B. Ebanman and L. Persson. Size-structured populations. Springer-Verlag, New York.

Wursig, B. 1986. Delphid foraging strategies. Pages 347-359 in R. Schusterman, R. Thomas, and F. G. Wood, editors. Dolphin cognition and behavior; a comparative approach. Lawrence Erlbaum Associates, Hillsdale, New Jersey.

Wursig, B. 1988. The behavior of baleen whales. Scientific American 255(4): 102-107. 